\title{
A hypoplastic macroelement model for a caisson foundation in sand under monotonic and cyclic loadings
}

\author{
Zhuang Jin ${ }^{\mathrm{a}}$, Zhen-Yu Yin ${ }^{\mathrm{d}, *}$, Panagiotis Kotronis ${ }^{\mathrm{a}}$, Zheng $\mathrm{Li}^{\mathrm{b}, * *}$, Claudio Tamagnini ${ }^{\mathrm{c}}$ \\ a École Centrale de Nantes, Université de Nantes, CNRS, Institut de Recherche en Génie Civil et Mécanique (GeM), UMR 6183, 1 rue de la Noë, BP \\ 92101, 44321, Nantes, cedex 3, France \\ ${ }^{\mathrm{b}}$ IFSTTAR, GERS, SV, Bouguenais, France \\ ${ }^{\mathrm{c}}$ Department of Civil and Environmental Engineering, Università degli Studi di Perugia, Perugia, Italy \\ ${ }^{\mathrm{d}}$ Department of Civil and Environmental Engineering, The Hong Kong Polytechnic University, Kowloon, Hong Kong, China
}

\begin{abstract}
Nowadays, the numerical analysis of caisson foundations of offshore structures is a big challenge in engineering design. A simple, fast and accurate numerical tool is proposed in this article based on the macroelement concept. The novel macroelement is within the framework of hypoplasticity and can consider static monotonic and cyclic combined (multidirectional) loads for a caisson foundation in sand. The incremental nonlinear constitutive formulas are defined in terms of generalised forces and displacements and an enhanced function of failure surface is introduced. A series of well-documented laboratorial reduced-scale $1 \mathrm{~g}$ model tests are adopted to validate the novel numerical tool. Results demonstrate a satisfied predictive performance of the proposed macroelement that can be used in caisson foundation design and constitutes an alternative to the traditional finite element analysis.
\end{abstract}

\section{Introduction}

Caisson foundations are traditionally used for offshore structures such as oil and gas platforms, tension leg platforms or floating platforms [1]. During the last decade, the increasing application of caisson foundations for offshore wind turbines has proven to be a cost-effective alternative to gravity-based foundations and monopiles. Caisson foundations are made of steel and are usually subjected to vertical and long-duration monotonic or cyclic horizontal loads and moments that are transferred to the foundation through the footing beneath the structure [2-5]. For an optimum design, understanding the performance of caisson foundations under combined (multidirectional) loading is therefore necessary.

The finite element method is widely adopted to analyse the nonlinear behaviour of caisson foundations [6-10]. Nevertheless, nonlinear finite element analyses are time-consuming and require considerable skill. A high-efficient and convenient practical strategy to reproduce the nonlinear behaviour of foundations under combined loadings is the so-called macroelement approach introduced in geotechnical engineering [11-14]. In this approach, the nonlinear behaviour of the soil-foundation system is expressed in terms of generalised forces and displacements through a reference point [15]. The 2D or 3D stress resultant constitutive law is expressed following the plasticity or the hypoplasticity theory.

The first developments of the macroelement approach were for shallow footings under monotonic loading conditions [15-20].

\footnotetext{
${ }^{*}$ Corresponding author.

** Corresponding author.

E-mail addresses: zhenyu.yin@polyu.edu.hk (Z.-Y. Yin), zheng.li@ifsttar.fr (Z. Li).
} 
More recently, the attention has been focused on the simulation of the cyclic/dynamic response of shallow footings for seismic analysis. Paolucci [21] adopted an elastic-perfectly plastic macroelement with a non-associated flow rule. Crémer et al. [22,23] developed an isotropic/kinematic hardening macroelement for cyclic/dynamic loading conditions and Grange et al. [24] proposed a multi-mechanism, isotropic/kinematic hardening model considering the overturning mechanism and uplift. Further contributions in this field can be for example found in Refs. [25-31]. Recent developments concern the spudcan behaviour for jack-ups [18,32-34] and caissons on clay [35] or on sand [36]. Chatzigogos et al. [37] conceived a bounding surface hyperplastic model for shallow foundation and Nguyen-Sy [38] proposed a hyperplastic model for the cyclic and seismic response of caisson foundations on sand. The framework of hyperplasticity is based on the thermodynamic theory. The key feature of the approach is to specify fully the constitutive behaviour of materials by using the free energy function and the dissipation function [39,40]. All the aforementioned macroelement models were developed within the framework of the classical (isotropic or anisotropic) theory of plasticity. Alternatively, macroelement models considering the rate-type constitutive equations of hypoplasticity [41-43] have been developed for shallow (Salciarini and Tamagnini [44], Tamagnini et al. [45]) and pile foundations (Li et al. [46,47]).

The aim of this paper is to study the response of a caisson foundation in sand under static monotonic and cyclic loadings with a novel macroelement developed under the framework of hypoplasticity. First, a brief description of the macroelement's mathematical formulation is presented. An enhanced failure surface is introduced and the macroelement parameters are calibrated using one monotonic and one cyclic indoor model tests. Finally, further model tests are used to evaluate the predictive performance of the model.

\section{Hypoplastic macroelement model}

\subsection{Development of macroelement model}

The hypoplasticity macroelement for shallow foundations and deep foundations introduced by Salciarini and Tamagnini [44] and Li et al. [46,47] is used as a starting point to develop a hypoplastic macroelement for a caisson foundation in sand for static monotonic and cyclic loadings. The general framework is briefly given hereafter. The following definitions are adopted hereafter: bold letters define tensors, $\|\cdot\|$ the norm of a tensor and $(\cdot)$ the derivative with respect to time.

The mechanical response of the caisson foundation is described by means of a generalised load vector $t$ and a generalised displacement vector $\boldsymbol{u}$ defined as:

$$
\begin{aligned}
& \boldsymbol{t}:=\{V, H, M / D\}^{T} \\
& \boldsymbol{u}:=\{w, u, D \theta\}^{T}
\end{aligned}
$$

where $H, V$ and $M$ are the horizontal force, the vertical force and the moment applied to the caisson, $w, u$ and $\theta$ the vertical displacement, the horizontal displacement and the rotation respectively. The characteristic length $D$ is the caisson diameter used to homogenise the dimensions of the components of $\boldsymbol{t}$ and $\boldsymbol{u}$. The generalised velocity vector $\boldsymbol{d}$ is defined as:

$$
\boldsymbol{d}:=\dot{\boldsymbol{u}}
$$

The hypoplastic macroelement formulation in rate-form for monotonic loading conditions reads:

$$
\begin{aligned}
& \dot{\boldsymbol{t}}=\mathcal{K}(\boldsymbol{t}, \boldsymbol{q}, \boldsymbol{d}) \boldsymbol{d} \\
& \mathcal{K}=\boldsymbol{L}(\boldsymbol{t}, \boldsymbol{q})+\boldsymbol{N}(\mathrm{t}, \mathrm{q}) \eta^{T} \\
& \eta=\frac{\boldsymbol{d}}{\|\boldsymbol{d}\|}
\end{aligned}
$$

where $\boldsymbol{q}$ is a pseudo-vector of internal variables accounting for the effects of the previous loading history.

The tangent stiffness $\mathcal{K}(\boldsymbol{t}, \boldsymbol{q}, \boldsymbol{d})$ differs from the classical elasto-plastic tangent stiffness in that it varies continuously with the direction $\boldsymbol{\eta}$ of the generalised velocity, a property known as incremental nonlinearity. It has two components, a "linear" term $\boldsymbol{L}(\boldsymbol{t}, \boldsymbol{q})$ and a "nonlinear" term $\boldsymbol{N}(\mathrm{t}, \mathrm{q})$. The "linear" term describes the initial linear constitutive relationship of the macroelement. With the variation of the stress state however, the "linear" behaviour is continuously modified by $\boldsymbol{N}(\mathrm{t}, \mathrm{q})$.

In order to consider cyclic loadings, the "internal displacement" $\boldsymbol{\delta}$ is introduced as internal variable, as proposed by Niemunis and Herle [48] and Salciarini and Tamagnini [44]. The constitutive equation of the hypoplastic model is thus modified as follows:

$$
\dot{\boldsymbol{t}}=\mathcal{K}(\boldsymbol{t}, \boldsymbol{q}, \boldsymbol{d}, \delta) \boldsymbol{d}
$$

$$
\mathcal{K}=\left[\rho^{\chi} m_{T}+\left(1-\rho^{\chi}\right) m_{R}\right] \mathbf{L}+\left\{\begin{array}{l}
\rho^{\chi}\left(1-m_{T}\right)\left(\mathbf{L} \eta_{\delta}\right) \eta_{\delta}^{T}+\rho^{\chi} \mathbf{N} \eta_{\delta}^{T}\left(\boldsymbol{\eta}_{\delta} \cdot \boldsymbol{\eta}>0\right) \\
\rho^{\chi}\left(m_{R}-m_{T}\right)\left(\mathbf{L} \boldsymbol{\eta}_{\delta}\right) \eta_{\delta}^{T}\left(\boldsymbol{\eta}_{\delta} \cdot \boldsymbol{\eta} \leq 0\right)
\end{array}\right.
$$

where $\chi, m_{T}$, and $m_{R}$ are constants.

The evolution rate of the internal displacement is defined as: 


$$
\dot{\delta}=\left\{\begin{array}{l}
\left(\mathscr{I}-\rho^{\beta_{r}} \eta_{\delta} \eta_{\delta}^{T}\right) \boldsymbol{d} \\
\boldsymbol{d} \quad\left(\eta_{\delta} \cdot \eta \leq 0\right)
\end{array} \quad\left(\eta_{\delta} \cdot \eta>0\right)\right.
$$

where $\mathscr{I}$ is the identity matrix, the scalar $0 \leq \rho \leq 1$ is the normalized magnitude of $\eta_{\delta}, \rho=\left(\frac{\left\|\eta_{\delta}\right\|}{R}\right)$, $\beta_{r}$ and $R$ are two model constants and:

$$
\eta_{\delta}= \begin{cases}\delta /\|\delta\| & (\delta \neq 0) \\ 0 & (\delta=0)\end{cases}
$$

By comparing Eqs. (4)-(6) it can be observed that both the "linear" and "nonlinear" terms of the constitutive relationship are modified to reproduce cyclic loadings. The matrix $\mathbf{L}$, which accounts for the stiffness at a load reversal point, is defined as:

$$
\begin{aligned}
& \mathbf{L}=\frac{1}{m_{R}} \mathcal{K}^{e} \\
& \mathcal{K}^{e}:=\left[\begin{array}{ccc}
k_{v v} & 0 & 0 \\
0 & k_{h h} & k_{h m} \\
0 & k_{h m} & k_{m m}
\end{array}\right]
\end{aligned}
$$

where $\mathcal{K}^{e}$ is the elastic stiffness matrix and $k_{v v}, k_{h h}, k_{m m}$ and $k_{h m}$ define the vertical, horizontal, rotational and coupled horizontalrotational stiffness of the foundation system respectively. The influences of stiffness for the lid and the skirt have been comprehensively discussed in the work of Skau et al. [49]. Note that the caisson foundation in this study is regarded as a rigid body. The flexibility of the lid and the skirt could be considered as suggested by Skau et al. [49]. As was the case for pile foundations [46,47], the coupled effect between horizontal forces and moment must be considered for the caisson foundation because of the skirt.

The nonlinear function $\boldsymbol{N}$ can be expressed as:

$$
\boldsymbol{N}(\boldsymbol{t})=-Y(\boldsymbol{t}) \mathbf{L m}(\boldsymbol{t})
$$

where $Y(\boldsymbol{t})$ is the scalar function which controls the degree of nonlinearity; and $\boldsymbol{m}(\boldsymbol{t})$ is the unit gradient which describes the plastic flow direction. In order to correctly define these two items in the hypoplasticity constitutive equation (eq. (11)), two important surfaces need to be introduced, i.e. the ultimate failure surface $F(t)$ and the loading surface $f(t)$.

In order to establish the ultimate failure (capacity) surface $F(t)$ for caisson foundation, in this study, numerical investigation was adopted to find the 3D failure surface with details as follows. Different loading paths were numerically chosen to investigate the form of the failure surface in the $H-M$ plane [50]. As shown in Fig. 1, a constant vertical load was first applied to the LRP (Loading Reference Point) of the caisson foundation up to a specified value. Then, radial displacement loadings were imposed (constant ratio of the rotation-displacements increments) to reach the ultimate strength, a similar approach for determination the shape of the failure envelope was also adopted in Refs. [30,51,53]. The failure loci points were defined as the final loading points of the different loading paths, shown in Fig. 2. The experimental model test results of Foglia et al. [53] were also used to validate and extend the approach.

A mathematical formula is presented hereafter to describe the failure surface in the $H: M / D$ loading plane. Following the work of Nova and Montrasio [13] and inspired by the work of Villalobos et al. [54], the inclined failure envelope can be described as:

$$
F=\left(\frac{H}{h_{i} V_{0}}\right)^{2}+\left(\frac{M}{D m_{i} V_{0}}\right)^{2}+2 e \frac{H}{h_{i} V_{0}} \frac{M}{D m_{i} V_{0}}-1=0
$$

where $V_{O}$ is the vertical bearing capacity of the foundation, the fitting parameters $h_{i}$ and $m_{i}$ represent the intersection of each ellipse with the $H / V_{o}$ and $M /\left(D V_{o}\right)$ axes respectively, and $e$ is the eccentricity of the ellipse. Using a least-squares regression, Eq. (12) was calibrated to fit the failure loci points obtained from simulations under different loading combinations [50] and monotonic model tests [53], shown in Fig. 3.

More specifically, Fig. 4 shows the calibrated values of $h_{\mathrm{i}}$ and $m_{\mathrm{i}}$ as a function of the normalized vertical load $V / V_{0}$. The apex of the failure surface for low vertical loads has a negative value because of the tension capacity of the caisson foundation. Eqs. (13) and (14) were proposed to provide the fitting functions, similar but simpler than the formulas proposed by Villalobos et al. [54]:

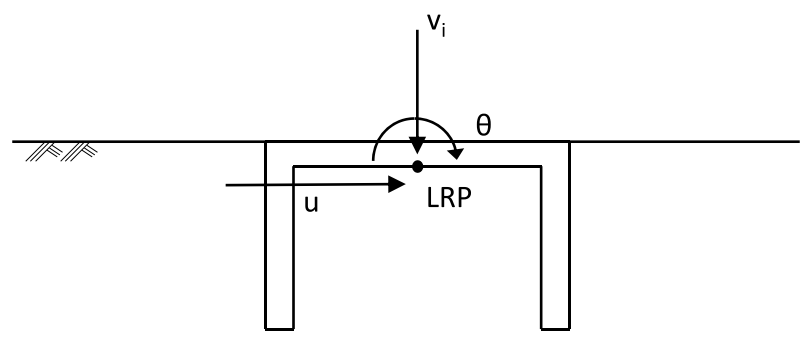

Fig. 1. Caisson foundation, LRP (Loading Reference Point), vertical force and radial displacement loading in the $H-M$ plane. 


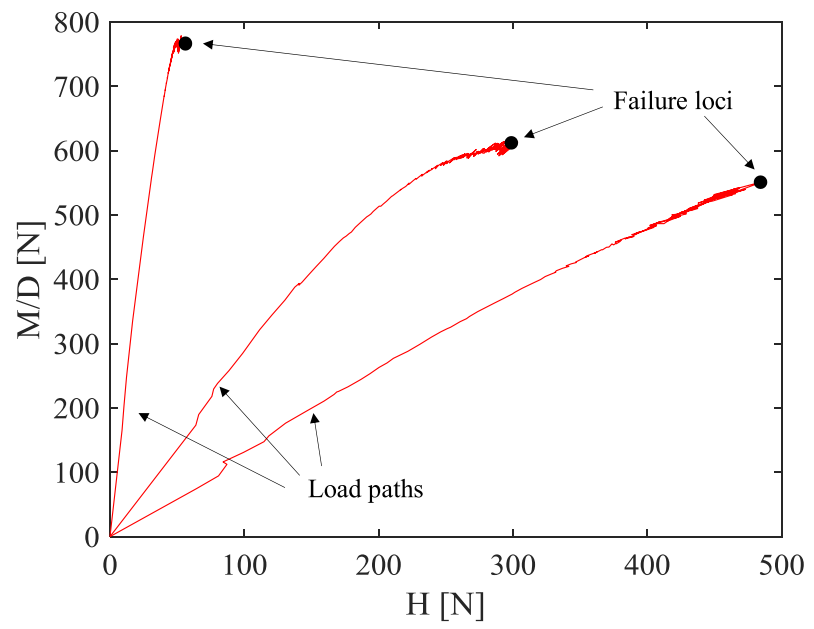

Fig. 2. Determination of the failure loci for different load paths.

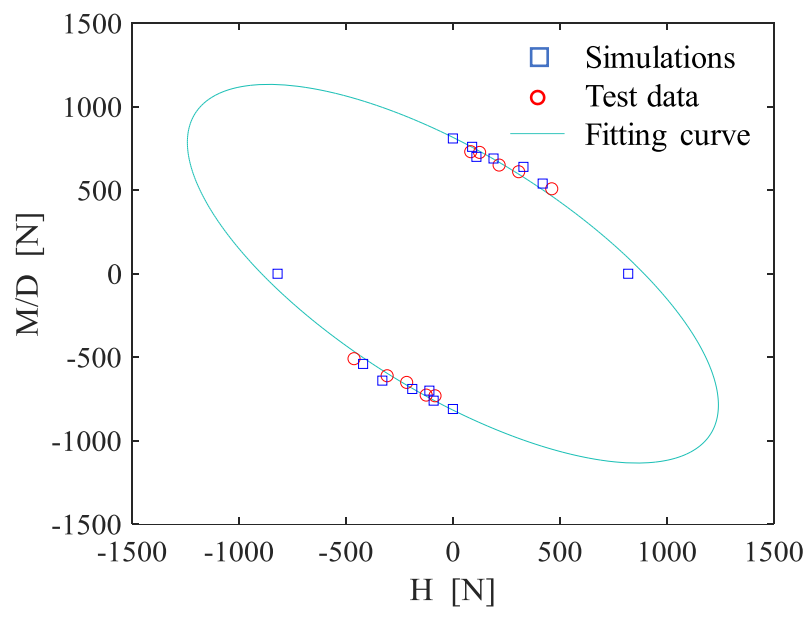

Fig. 3. Failure envelope in the H:M/D loading plane: fitting curve based on model tests data and numerical simulation results.

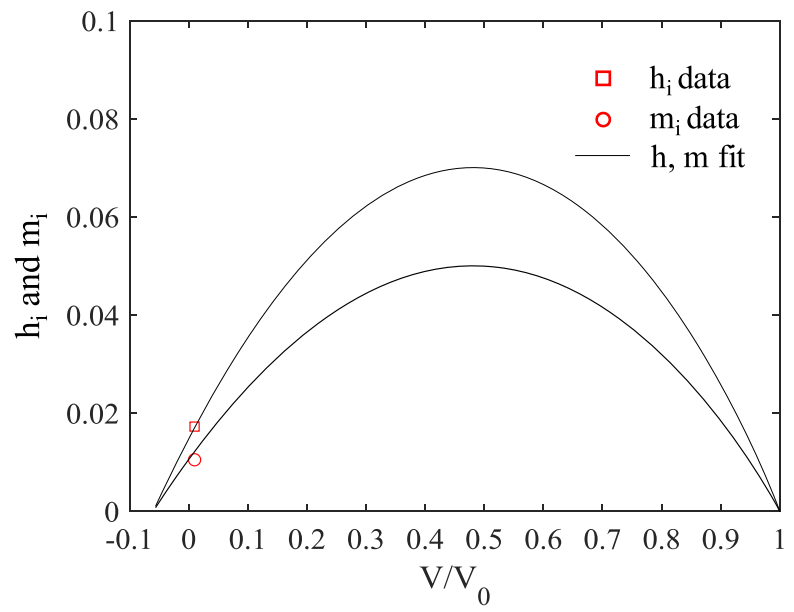

Fig. 4. $h_{i}$ and $m_{i}$ as functions of the normalized vertical load $V / V_{0}$. 
Table 1

Parameters of the hypoplastic macroelement for a caisson foundation in sand.

\begin{tabular}{|c|c|c|c|}
\hline Group & Parameters & Description & Value \\
\hline \multirow[t]{6}{*}{ Failure surface } & $V_{0}(\mathrm{kN})$ & Vertical bearing capacity & 90 \\
\hline & $t_{0}(-)$ & Tension factor & 0.06 \\
\hline & $e(-)$ & Eccentricity of the failure surface & 0.91 \\
\hline & $h_{0}(-)$ & Dimension of the failure surface (horizontal) & 0.068 \\
\hline & $m_{0}(-)$ & Dimension of the failure surface (moment) & 0.045 \\
\hline & $\beta_{1}, \beta_{2}(-)$ & Shaping factors of the failure surface & $0.96,0.97$ \\
\hline \multirow[t]{4}{*}{ Pseudo-elastic stiffness } & $k_{v v}(\mathrm{kN} / \mathrm{m})$ & Vertical stiffness & 3100 \\
\hline & $k_{h h}(\mathrm{kN} / \mathrm{m})$ & Horizontal stiffness & 3200 \\
\hline & $k_{m m}(\mathrm{kN} / \mathrm{m})$ & Rotational stiffness & 1800 \\
\hline & $k_{h m}, k_{m h}(\mathrm{kN} / \mathrm{m})$ & Coupled translation-rotation stiffness & 2500 \\
\hline Hardening parameter & $\kappa(-)$ & Scaling function constant & 1.1 \\
\hline \multirow[t]{5}{*}{ Cyclic behaviour (internal displacement) } & $m_{R}(-)$ & Stiffness at load reversal point & 10 \\
\hline & $m_{T}(-)$ & Stiffness when neutral loading & 2 \\
\hline & $R(-)$ & Range of linearity & 0.006 \\
\hline & $\beta^{r}(-)$ & Rate of evolution of internal displacement & 0.5 \\
\hline & $\mathrm{x}(-)$ & Transition of stiffness & 0.5 \\
\hline
\end{tabular}

$$
\begin{aligned}
& h_{i}=\frac{H_{i}}{V_{0}}=h_{0}\left(\frac{\beta_{1}^{\beta_{1}}+\beta_{2}^{\beta_{2}}}{t_{0}+1}\right)^{\left(\frac{\beta_{1}+\beta_{2}}{\beta_{1} \beta_{2}}\right)}\left(\frac{V}{V_{0}}+t_{0}\right)^{\beta_{1}}\left(1-\frac{V}{V_{0}}\right)^{\beta_{2}} \\
& m_{i}=\frac{M_{i}}{V_{0}}=m_{0}\left(\frac{\beta_{1}^{\beta_{1}}+\beta_{2}^{\beta_{2}}}{t_{0}+1}\right)^{\left(\frac{\beta_{1}+\beta_{2}}{\beta_{1} \beta_{2}}\right)}\left(\frac{V}{V_{0}}+t_{0}\right)^{\beta_{1}}\left(1-\frac{V}{V_{0}}\right)^{\beta_{2}}
\end{aligned}
$$

where $\beta_{1}$ and $\beta_{2}$ are shaping factors, generally close to unity, determined using a trial-error procedure. The upper limit of $\beta_{1}$ and $\beta_{2}$ is 1 as larger values make the failure envelope concave [55]. $V_{o}$ can be determined numerically, by applying a pure vertical load up to failure. $h_{0}$ and $m_{0}$ are the maximum values of $h_{i}$ and $m_{i}$ over the full range of $V / V_{0}$. They are found approximately for $V / V_{0}=0.4-0.5$. The dimensionless quantity $t_{0}$ controls the tension loading that the caisson foundation can sustain (tension capacity) and can be obtained as a function of the skirt thickness to the caisson diameter [56,57]. The two shaping factors $\beta_{1}$ and $\beta_{2}$ are hereafter determined using a trial-error procedure from the model tests conducted by Foglia et al. [53]. Note that Eqs. (13) and (14) can be used for unifying different vertical load levels. All the macroelement constants are summarized in Table 1.

Eqs. (12)-(14) can be combined to represent an inclined parabolic ellipsoid in the 3D H-M-V space (see Fig. 5), as follows:

$$
F=\left(\frac{H}{h_{0} V_{0}}\right)^{2}+\left(\frac{M}{D m_{0} V_{0}}\right)^{2}+2 e \frac{H}{h_{0} V_{0}} \frac{M}{D m_{0} V_{0}}-F_{V}\left(V, V_{t}, V_{0}\right)=0
$$

where

$$
F_{V}\left(V, V_{t}, V_{0}\right)=\beta_{12}^{2}\left(\frac{V}{V_{0}}+t_{0}\right)^{2 \beta_{1}}\left(1-\frac{V}{V_{0}}\right)^{2 \beta_{2}}, \beta_{12}=\left(\frac{\beta_{1}^{\beta_{1}}+\beta_{2}^{\beta_{2}}}{t_{0}+1}\right)^{\left(\frac{\beta_{1}+\beta_{2}}{\beta_{1} \beta_{2}}\right)}
$$

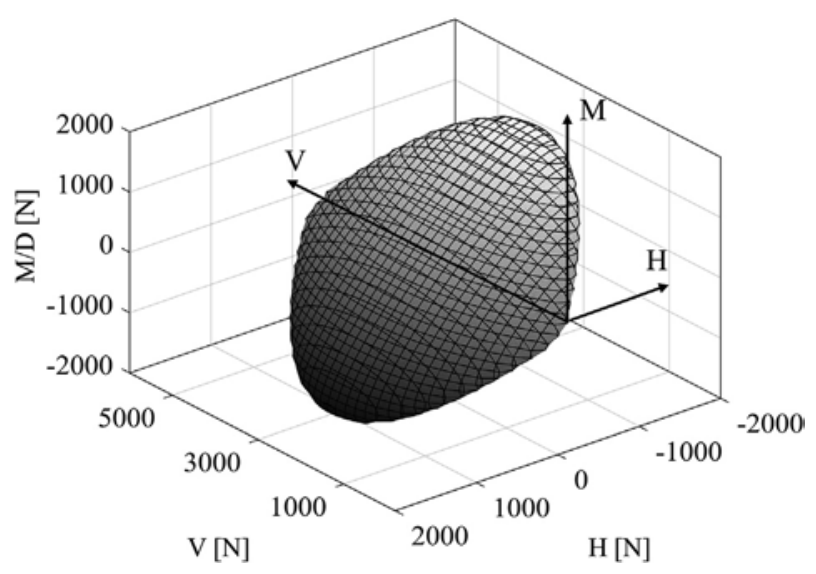

Fig. 5. Failure surface in the 3D $H-M-V$ space. 


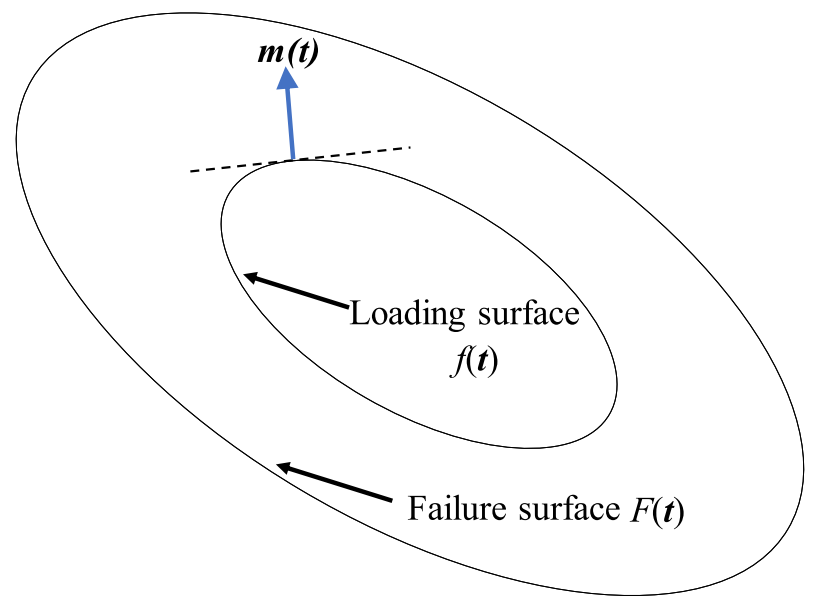

Fig. 6. The unit gradient of the loading surface: $m(t)$.

In the framework of hypoplasticity, $F(t)$ is the bound of bearing capacity for caisson foundation which functions as a bounding surface. When the stress state approaches the bounding surface, plasticity is developing and at the bounding surface the full plastic state is reached. It is assumed that the current stress state lies on a so-called loading surface, $f(t)$, which has the same shape as the bounding surface but with a smaller size, shown in Fig. 6.

With the development of plasticity, the loading surface will expand as isotropic as the bounding surface. The degree of nonlinearity is measured by the scalar function $Y(\boldsymbol{t})$ defined as:

$$
Y(\boldsymbol{t})=\xi^{\varkappa}
$$

where $\kappa$ is a material constant that controls the evolution of the loading function; and $\xi \in[0,1]$, measures the distance between the loading surface $f(\boldsymbol{t})$ and failure surface $F(\boldsymbol{t})$.

From a geometric point of view as shown in Fig. 6, the loading surface $f(t)$ which has a coincident shape compared to the failure surface $F(t)$ but of smaller size can be described as:

$$
f=\left(\frac{H}{h_{0} V_{0}^{*}}\right)^{2}+\left(\frac{M}{D m_{0} V_{0}^{*}}\right)^{2}+2 e \frac{H}{h_{0} V_{0}^{*}} \frac{M}{D m_{0} V_{0}^{*}}-\beta_{12}^{2}\left(\frac{V}{V_{0}^{*}}+t_{0}\right)^{2 \beta_{1}}\left(1-\frac{V}{V_{0}^{*}}\right)^{2 \beta_{2}}=0
$$

with:

$$
V_{0}^{*}=\xi V_{0} \leq V_{0}
$$

The current stress state $(H, M, V)$ must lie on the loading surface with $\xi \in[0,1]$. By substituting current stress state $(H, M, V)$ to eq. (18), we can have a nonlinear function with respect to variable $\xi$. The root value of $\xi \in[0,1]$ can be determined by numerical approaches such as Newton-Raphson or bisection algorithm. In this study, the bisection method was simply adopted to calculate $\xi$.

$\boldsymbol{m}(\boldsymbol{t})$ in Eq. (11) is the normalized plastic flow direction taken as the normalized gradient of the loading function at the current loading state (see Fig. 6). An associative plastic flow rule is adopted and $\boldsymbol{m}(\boldsymbol{t})$ is given by:

$$
\boldsymbol{m}(\boldsymbol{t})=\frac{\partial f / \partial \boldsymbol{t}}{\|\partial f / \partial \boldsymbol{t}\|}
$$

where $f$ is the above-mentioned loading function homothetic to $F=0$ passing through $t$.

\subsection{Synthesis of the macroelement parameters}

Macroelement constants can be divided into four groups, see Table 1. Six of them describe the failure surface; four stiffness coefficients define the pseudo-elastic behaviour; one hardening constant controls the stiffness decay of the macroelement response for monotonic loadings; and five constants control the response for cyclic loadings.

\section{Calibration and validation}

\subsection{Model tests}

The hypoplastic macroelement for caisson foundations in sand has been implemented into the MATLAB based finite element toolbox FEDEASLab [58]. Numerical simulations and the model tests conducted by Foglia et al. [53] are compared to identify and calibrate the macroelement parameters. 

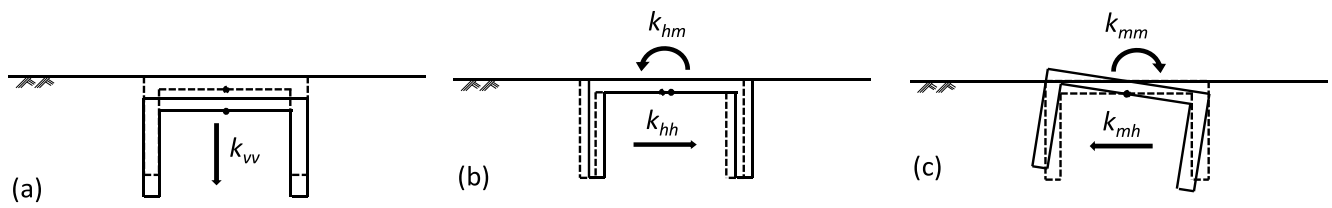

Fig. 7. Different loading configurations to determine the pseudo-elastic stiffness coefficients.

The experimental set-up by Foglia et al. [53] consisted of a sandbox (1600 mm $\times 1600 \mathrm{~mm} \times 1150 \mathrm{~mm})$, a loading frame and a hinged beam. A system of steel cables and pulleys has been used to apply loads to the foundation through an electric motor drive positioned on the hinged beam. The load, set by means of three weight hangers, was transferred to the foundation through a vertical beam bolted onto the caisson lid. The foundation was instrumented with three LVDTs (Linear Variable Differential Transformer) and two load cells. The caisson foundation was constructed of steel, with an outer diameter of $300 \mathrm{~mm}$, a lid thickness of $11.5 \mathrm{~mm}$, a skirt length of $300 \mathrm{~mm}$ and a skirt thickness of $1.5 \mathrm{~mm}$. Various tests under different loading combinations have been carried out.

In the following, five dimensionally homogeneous monotonic moment-to-horizontal load ratios tests and two cyclic model tests at constant vertical load have been simulated numerically to identify and calibrate the macroelement constants and then to validate its performance.

\subsection{Identification and calibration of the macroelement parameters}

The pseudo-elastic stiffness coefficients of the macroelement are identified using adequate loading conditions and numerical simulations, (see Fig. 7, similar to Li et al. [46], Jin et al. [50] and Cheng [59]). One can also use the work of Cheng [59] that provides the elasticity coefficients for caisson foundations. For example, the coupling stiffness $k_{m h}$ is obtained by applying a small horizontal displacement at the LRP while the rotation is kept fixed. Results are summarized in Table 1.

The model test with the monotonic loading combination $M / D H=3.01$ of Foglia et al. [53] has been chosen to calibrate the hardening parameter $\kappa$. Additional macroelement simulations for different values of $\kappa$ and for the same loading path have also been performed. Results are given in the H:u plane in Fig. 8. Based on the comparison between the experimental and the simulation results, a value $\kappa=1.1$ has been adopted for the loading function constant.

The cyclic response macroelement constants have been calibrated by trial and error using model test with the cyclic loading combination $M / D H=1.987$ of Foglia et al. [53]. The loading frequency is $f=0.1 \mathrm{~Hz}$ and the number of cycles $(N) 5 \times 10^{4}$. Calibration is facilitated by the fact that the macroelement model response is not so sensitive to the constants $\beta^{r}$ and $\mathrm{x}$. The size of the pseudo-elastic domain $R$ can be guessed from the length of the quasi-linear portion of the load-displacement curves upon unloading or reloading, while the parameters $m_{R}$ and $m_{T}$ affect the ratio between the system stiffness under reverse or tangential loading and continued loading conditions. The calibrated values of the five cyclic constants are summarized in Table 1. Comparison between the experimental results and the macroelement simulations is shown in Fig. 9(a) and Fig. 9(c), where only the first 100 cycles are presented. Numerical simulations performed by Foglia et al. [53] are also plotted in Fig. 9(b). Here, The macroelement model presented in Foglia et al. [53] originated from an existing model [13] within the framework of work-hardening plasticity. The numerical results adequately describe the observed response of the system in the combined horizontal-moment cyclic loading test, indicating that the calibrated values of the macroelement constants controlling the cyclic response are reasonable.

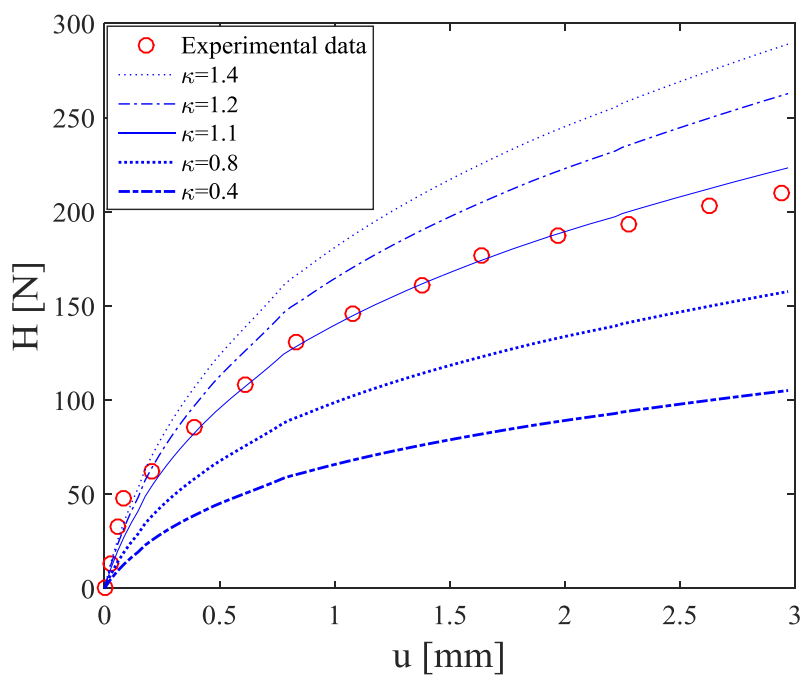

Fig. 8. Numerical and experimental results for different values of the hardening parameter $\kappa$ 

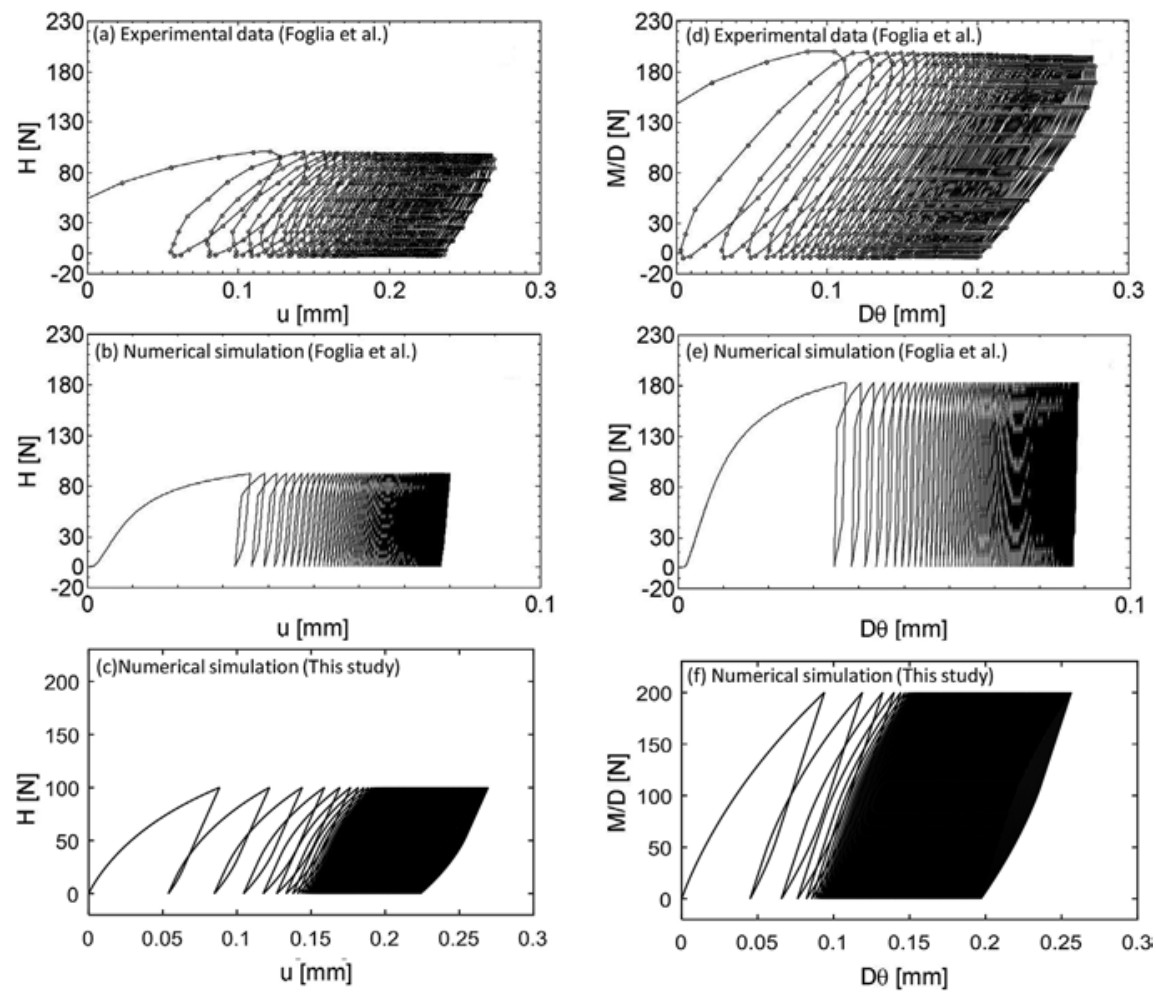

Fig. 9. Horizontal displacement $(u)$ versus horizontal load $(H)$ for (a) experimental results, Foglia et al. [53] (b) simulated results, Foglia et al. [53], (c) macroelement results; and rotational displacement $(D \theta)$ versus dimensionally homogeneous moment $(M / D)$ for $(\mathrm{d})$ experimental results, Foglia et al. [53] (e) simulated results, Foglia et al. [53], (f) macroelement results.

Note that all the macroelement constants can be also identified by inverse analysis using optimization methods [60-65].

\subsection{Validation of the macroelement}

Five monotonic tests [53] and one cyclic test [66] are adopted hereafter to evaluate the predictive capabilities of the macroelement. The monotonic tests were conducted at five different dimensionally homogeneous moment-to-horizontal load ratios ( $M$ / $D H=1.1,1.987,3.01,5.82,8.748)$. The cyclic test was carried out for $M / D H=1.987, M_{\min }=-5 \mathrm{~N} \cdot \mathrm{m}, M_{\max }=75 \mathrm{~N} \cdot \mathrm{m}, H_{\min }=-10 \mathrm{~N}$ and $H_{\max }=125 \mathrm{~N}$. The loading frequency was $f=0.1 \mathrm{~Hz}$ and the number of cycles $N=5 \times 10^{4}$. The parameters of Table 1 are adopted in the macroelement simulations. Only the first 100 cycles are simulated and compared with the experimental response.

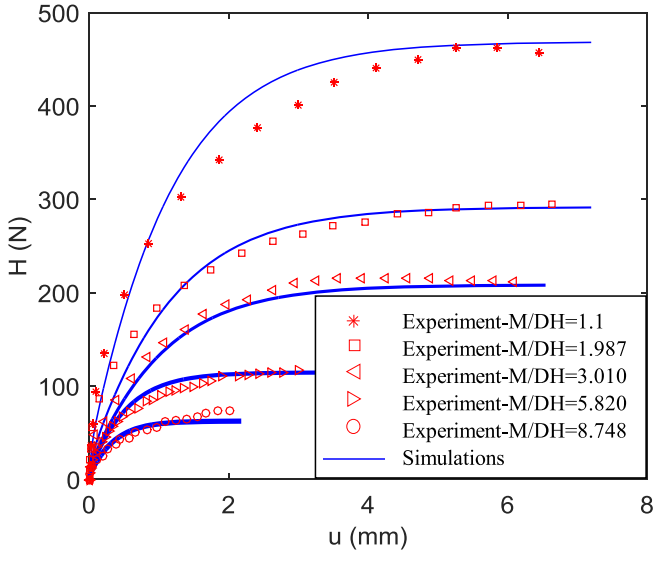

(a)

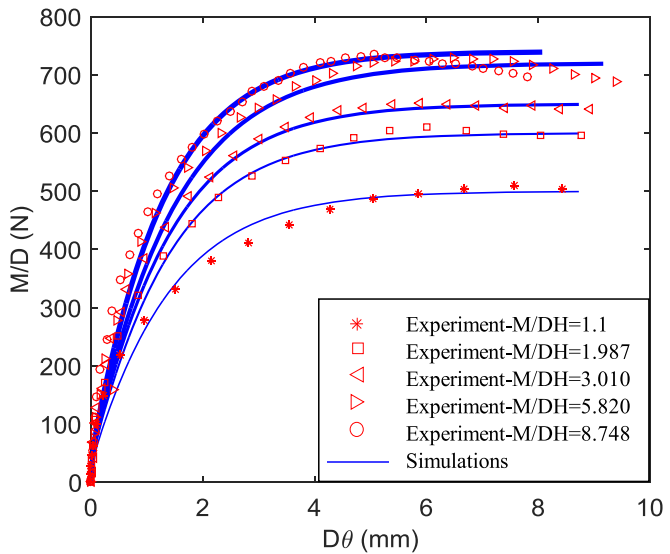

(b)

Fig. 10. Comparison between the experimental model test results and the macroelement predictions under combined loadings M/DH: (a) H-u and (b) M/D-D $\theta$ curves. 

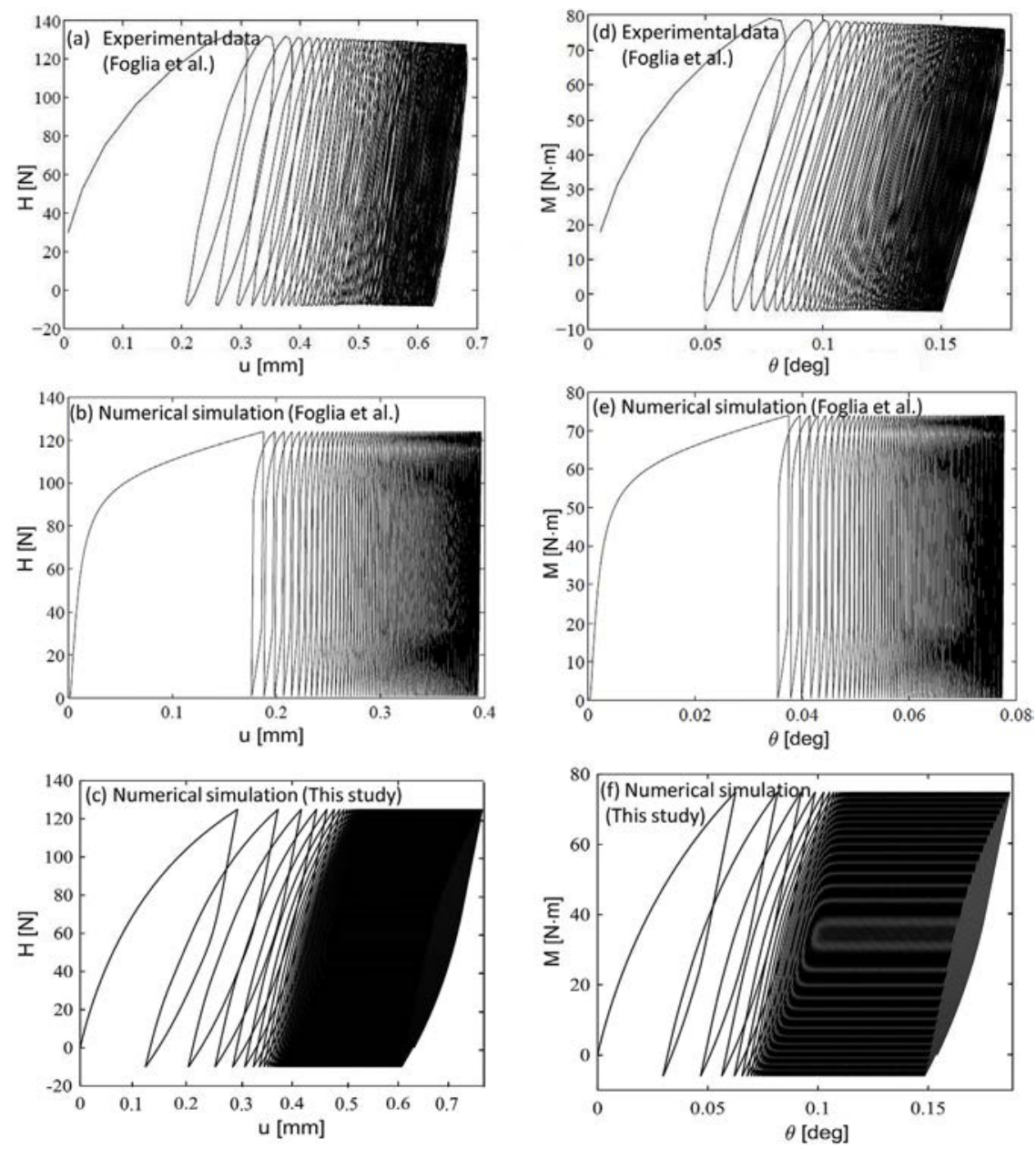

Fig. 11. Horizontal displacement $(u)$ versus horizontal load $(H)$ for (a) experimental results, Foglia et al. [53] (b) simulated results, Foglia et al. [53], (c) macroelement results; and rotational angle $(\theta)$ versus moment $(M)$ for (d) experimental results, Foglia et al. [53] (e) simulated results, Foglia et al. [53], (f) macroelement results.

Fig. 10 shows the comparison between the experimental model test results and the macroelement predictions for the monotonic tests. A fairly good agreement is observed for all the five moment-to-horizontal load ratios. Fig. 11 illustrates the comparison between the experimental model test results and the macroelement predictions for the horizontal-rotational cyclic loading test. The macroelement prediction results are satisfactory, presenting even a better agreement in terms of accumulated permanent displacements that the numerical simulations of Foglia et al. [53].

Overall, the coupling between the horizontal and rotational responses is well reproduced by the macroelement for both monotonic and cyclic loading conditions.

\section{Conclusion}

In this study, a novel macroelement for caisson foundations in sand has been proposed within the framework of the theory of hypoplasticity. The incremental nonlinear constitutive equations have been defined in terms of generalised forces, displacements and rotations and the "internal displacement" concept has been incorporated to take into account the effects of previous loading history under cyclic loading. An enhanced function has been proposed for the failure surface, in order to take into account multiple directional couplings.

A series of well-documented laboratorial reduced-scale $1 \mathrm{~g}$ model tests have been used to calibrate the macroelement constants and to assess its performance. Comparisons between predictions and experimental results demonstrate that the proposed macroelement is capable of reproducing the behaviour of caisson foundations in sand subjected to monotonic and cyclic loadings.

It is worth noting that the efficiency of the macroelement is much higher than that of conventional nonlinear 3D finite element simulations in terms of computational costs. This advantage is of particular importance for practical applications where the caisson foundation is subjected to a large number of cycles caused by environmental loadings, such as the ocean current and waves. The proposed macroelement is a useful tool for the design of caisson foundations in sand subjected to combined monotonic or cyclic 
loadings.

\section{Acknowledgements}

The financial supports from the National Natural Science Foundation of China (Grant NOs. 51579179, 51708009) are highly acknowledged. The authors also wish to acknowledge Dr. Qian ZHAO and Mr. Qilin TONG for their help of this study.

\section{References}

[1] Randolph M, Gourvenec S, White D, Cassidy M. Offshore geotechnical engineering. New York: Spon Press; 2011.

[2] Ibsen LB. Implementation of a new foundations concept for offshore wind farms. Nordisk Geoteknikermøte. Norsk Geoteknisk Forening; 2008 . p. 19-33.

[3] Byrne B, Houlsby G. Foundations for offshore wind turbines. Phil Trans Roy Soc Lond: Math Phys Eng Sci 2003;361:2909-30.

[4] Lesny K. Foundations for offshore wind turbines: tools for planning and design. VGE Verlag GmbH; 2010.

[5] Jin Z, Yin Z-Y, Kotronis P, Jin Y-F. Numerical analysis of a suction bucket penetrating in sand with a combined Lagrangian-SPH approach. Procedia Eng 2017;175:189-96.

[6] Gourvenec S. Effect of embedment on the undrained capacity of shallow foundations under general loading. Geotechnique 2008;58:177-86.

[7] Gerolymos N, Zafeirakos A, Karapiperis K. Generalized failure envelope for caisson foundations in cohesive soil: static and dynamic loading. Soil Dynam Earthq Eng 2015;78:154-74.

[8] Ntritsos N, Anastasopoulos I, Gazetas G. Static and cyclic undrained response of square embedded foundations. Geotechnique 2015;65:805-23.

[9] Bransby M, Yun G-J. The undrained capacity of skirted strip foundations under combined loading. Geotechnique 2009;59:115-25.

[10] Liu M, Yang M, Wang H. Bearing behavior of wide-shallow bucket foundation for offshore wind turbines in drained silty sand. Ocean Eng 2014;82:169-79.

[11] Butterfield R. Discussion: design parameters for granular soils. Proc 7th European conf on soil mech Fndn Engrg1979. p. 259-262.

[12] Schotman G. The effects of displacements on the stability of jackup spud-can foundations. Offshore technology conference: offshore technology conference; 1989. Houston, OTC 6026.

[13] Nova R, Montrasio L. Settlements of shallow foundations on sand. Geotechnique 1991;41:243-56.

[14] Cassidy M, Martin C, Houlsby G. Development and application of force resultant models describing jack-up foundation behaviour. Mar Struct 2004;17:165-93.

[15] Gottardi G, Houlsby G, Butterfield R. Plastic response of circular footings on sand under general planar loading. Geotechnique 1999;49:453-70.

[16] Cassidy M, Byrne B, Houlsby G. Modelling the behaviour of circular footings under combined loading on loose carbonate sand. Geotechnique 2002;52:705-12.

[17] Le Pape Y, Sieffert JG. Application of thermodynamics to the global modelling of shallow foundations on frictional material. Int J Numer Anal Methods Geomech 2001;25:1377-408.

[18] Martin C, Houlsby G. Combined loading of spudcan foundations on clay: numerical modelling. Geotechnique 2001;51:687-99.

[19] Montrasio L, Nova R. Settlements of shallow foundations on sand: geometrical effects. Geotechnique 1997;47:49-60.

[20] Houlsby G, Cassidy M. A plasticity model for the behaviour of footings on sand under combined loading. Geotechnique 2002;52:117-29.

[21] Paolucci R. Simplified evaluation of earthquake-induced permanent displacements of shallow foundations. J Earthq Eng 1997;1:563-79.

[22] Cremer C, Pecker A, Davenne L. Cyclic macro-element for soil-structure interaction: material and geometrical non-linearities. Int J Numer Anal Methods Geomech 2001:25:1257-84.

[23] Cremer C, Pecker A, Davenne L. Modelling of nonlinear dynamic behaviour of a shallow strip foundation with macro-element. J Earthq Eng 2002;6:175-211.

[24] Grange S, Kotronis P, Mazars J. A macro-element to simulate 3D soil-structure interaction considering plasticity and uplift. Int J Solids Struct 2009;46:3651-63.

[25] Chatzigogos C, Pecker A, Salencon J. Macroelement modeling of shallow foundations. Soil Dynam Earthq Eng 2009;29:765-81.

[26] Figini R, Paolucci R, Chatzigogos C. A macro-element model for non-linear soil-shallow foundation-structure interaction under seismic loads: theoretical development and experimental validation on large scale tests. Earthq Eng Struct Dyn 2012;41:475-93.

[27] Gajan S, Kutter BL. Contact interface model for shallow foundations subjected to combined cyclic loading. J Geotech Geoenviron Eng 2009;135:407-19.

[28] Gajan S. Physical and numerical modeling of nonlinear cyclic load-deformation behavior of shallow foundations supporting rocking shear walls. Davis: University of California; 2006.

[29] Shirato M, Paolucci R, Kouno T, Nakatani S, Fukui J, Nova R, et al. Numerical simulation of model tests of pier-shallow foundation systems subjected to earthquake loads using an elasto-uplift-plastic macro element. Soils Found 2008;48:693-711.

[30] Tistel J, Grimstad G, Eiksund GR. A macro model for shallow foundations on granular soils describing non-linear foundation behavior. Computers \& Structures. 2017.

[31] Skau KS, Grimstad G, Page AM, Eiksund GR, Jostad HP. A macro-element for integrated time domain analyses representing bucket foundations for offshore wind turbines. Mar Struct 2018;59:158-78.

[32] Zhang Y, Cassidy MJ, Bienen B. A plasticity model for spudcan foundations in soft clay. Can Geotech J 2014;51:629-46.

[33] Bienen B, Byrne B, Houlsby G, Cassidy M. Investigating six-degree-of-freedom loading of shallow foundations on sand. Geotechnique 2006;56:367-80.

[34] Vlahos G, Cassidy MJ, Byrne BW. The behaviour of spudcan footings on clay subjected to combined cyclic loading. Appl Ocean Res 2006;28:209-21.

[35] Cassidy M, Randolph M, Byrne B. A plasticity model describing caisson behaviour in clay. Appl Ocean Res 2006;28:345-58.

[36] Ibsen LB, Larsen Ka, Barari a. Calibration of failure criteria for bucket foundations on drained sand under general loading. J Geotech Geoenviron Eng 2014;140:04014033.

[37] Chatzigogos C, Figini R, Pecker A, Salençon J. A macroelement formulation for shallow foundations on cohesive and frictional soils. Int J Numer Anal Methods Geomech 2011;35:902-31.

[38] Nguyen-Sy L. The theoretical modelling of circular shallow foundation for offshore wind turbines. University of Oxford; 2005.

[39] Nguyen-Sy L, Houlsby GT. The theoretical modelling of a suction caisson foundation using hyperplasticity theory. Frontiers in Offshore Geotechnics II. 2005. p. 417. Perth.

[40] Byrne B, Houlsby G. Assessing novel foundation options for offshore wind turbines. World maritime technology conference: London: [sn]. 2006.

[41] Kolymbas D. An outline of hypoplasticity. Arch Appl Mech 1991;61:143-51.

[42] Niemunis A. Extended hypoplastic models for soils: Inst. für Grundbau und Bodenmechanik; 2003.

[43] Tamagnini C, Viggiani G, Chambon R. A review of two different approaches to hypoplasticity. Constitutive modelling of granular materials. Springer; 2000. p. $107-45$.

[44] Salciarini D, Tamagnini C. A hypoplastic macroelement model for shallow foundations under monotonic and cyclic loads. Acta Geotech 2009;4:163-76.

[45] Tamagnini C, Salciarini D, Ragni R. Implementation of 6-dof hypoplastic macroelement in a finite element code. COM Geo 2012. Proceedings of the 3rd international conference on computing for geospatial research and applications: association for Computing Machinery Washington, DC, USA. 2013. p. 60-71.

[46] Li Z, Kotronis P, Escoffier S, Tamagnini C. A hypoplastic macroelement for single vertical piles in sand subject to three-dimensional loading conditions. Acta Geotech 2016;11:373-90.

[47] Li Z, Kotronis P, Escoffier S, Tamagnini C. A hypoplastic macroelement formulation for single batter piles in sand. Int J Numer Anal Methods Geomech 2018;42:1346-65.

[48] Niemunis A, Herle I. Hypoplastic model for cohesionless soils with elastic strain range. Mech Cohesive-Frict Mater: Int J Exp Model Comput Mater Struct 1997;2:279-99.

[49] Skau KS, Jostad HP, Eiksund G, Sturm H. Modelling of soil-structure-interaction for flexible caissons for offshore wind turbines. Ocean Eng 2019;171:273-85. 
[50] Jin Z, Yin Z-Y, Kotronis P, Jin Y-F. Numerical investigation on evolving failure of caisson foundation in sand using the combined Lagrangian-SPH method. Mar Georesour Geotechnol 2018:1-13.

[51] Li Z, Kotronis P, Escoffier S. Numerical study of the 3D failure envelope of a single pile in sand. Comput Geotech 2014;62.

[53] Foglia A, Gottardi G, Govoni L, Ibsen LB. Modelling the drained response of bucket foundations for offshore wind turbines under general monotonic and cyclic loading. Appl Ocean Res 2015;52:80-91.

[54] Villalobos FA, Byrne BW, Houlsby GT. An experimental study of the drained capacity of suction caisson foundations under monotonic loading for offshore applications. Soils Found 2009;49:477-88.

[55] Ibsen LB, Barari A, Larsen KA. Adaptive plasticity model for bucket foundations. J Eng Mech 2013;140:361-73.

[56] Villalobos FA, Byrne BW, Houlsby GT. Moment loading of caissons installed in saturated sand. Proceedings of international symposium on frontiers in geotechnics, ISFOG university of Western2005. p. 411-416.

[57] Villalobos FA, Houlsby GT, Byrne BW. Suction caisson foundations for offshore wind turbines. Proc 5th Chilean conference of geotechnics (congreso chileno de Geotecnia), Santiago2004. p. 24-26.

[58] Filippou FC, Constantinides M. FEDEASLab getting started guide and simulation examples. NEESgrid Rep 2004;22:2004-5.

[59] Cheng N. Force-resultant models for shallow foundation systems and their implementation in the analysis of soil-structure interactions. University of Western Australia; 2015.

[60] Yin Z-Y, Jin Y-F, Shen S-L, Huang H-W. An efficient optimization method for identifying parameters of soft structured clay by an enhanced genetic algorithm and elastic-viscoplastic model. Acta Geotech 2017;12:849-67.

[61] Yin ZY, Jin YF, Shen JS, Hicher PY. Optimization techniques for identifying soil parameters in geotechnical engineering: comparative study and enhancement. Int J Numer Anal Methods Geomech 2018;42:70-94.

[62] Jin Y-F, Yin Z-Y, Wu Z-X, Zhou W-H. Identifying parameters of easily crushable sand and application to offshore pile driving. Ocean Eng 2018;154:416-29.

[63] Jin Y-F, Yin Z-Y, Shen S-L, Zhang D-M. A new hybrid real-coded genetic algorithm and its application to parameters identification of soils. Inverse Probl Sci Eng 2017;25:1343-66.

[64] Jin Y-F, Yin Z-Y, Shen S-L, Hicher P-Y. Selection of sand models and identification of parameters using an enhanced genetic algorithm. Int J Numer Anal Methods Geomech 2016;40:1219-40.

[65] Yin Z-Y, Jin Z, Kotronis P, Wu Z-X. Novel SPH SIMSAND-based approach for modeling of granular collapse. Int J Geomech 2018;18:04018156.

[66] Foglia A. Bucket foundations under lateral cyclic loading: submitted for the degree of doctor of philosophy. Department of Civil Engineering, Aalborg University; 2015. 